\title{
A single item screening question for fear of recurrence in head and neck cancer
}

\section{Rogers SN ${ }^{1,2}$, Cross B ${ }^{3}$, Talwar $C^{3}$, Lowe $D^{1,2}$, Humphris $\mathbf{G}^{4}$.}

Professor Simon N Rogers, FDS RCS FRCS MD, Evidence-Based Practice Research Centre (EPRC), Faculty of Health and Social Care, Edge Hill University, St Helens Road, Ormskirk, L39 4QP ${ }^{1}$ and Consultant Regional Maxillofacial Unit, University Hospital Aintree, Liverpool, L9 1AE, UK ${ }^{2}$. snrogers.aintree@gmail.com

Mr Ben Cross, Medical Student, Liverpool University, Cedar House Ashton Street, Liverpool L69 3GE, United Kingdom ${ }^{3}$. ben_cross1@ @otmail.com

Mr Cyrus Talwar, Medical Student, Liverpool University, Cedar House Ashton Street, Liverpool L69 3GE, United Kingdom ${ }^{3}$. C.Talwar@student.liverpool.ac.uk

Professor Derek Lowe, MSc C.Stat Medical Statistician, Evidence-Based Practice Research Centre (EPRC), Faculty of Health, Edge Hill University, St Helens Road, Ormskirk, L39 4QP ${ }^{1}$, Regional Maxillofacial Unit, University Hospital Aintree, Liverpool, L9 1AE, UK ${ }^{2}$ astraglobeltd@btconnect.com

Professor Gerry Humphris, PhD, CPsychol, Professor of Health Psychology, Bute Medical School, University of St Andrews, Westburn Lane, St Andrews, Fife, KY16 8HX, Scotland, UK ${ }^{4}$.gmh4@st-andrews.ac.uk

\section{Address for correspondence:}

Professor Simon N Rogers, FDS RCS FRCS MD, Consultant Regional Maxillofacial Unit, University Hospital Aintree, Liverpool, L9 1AE, UK. snrogers.aintree@gmail.com

\section{Running title: Screening question for fear of recurrence in head and neck cancer}

Key words: Fear of recurrence; Patient reported outcomes; Health related quality of life; Head and Neck cancer; UW-QOL 


\begin{abstract}
Background: Fear of recurrence (FoR) is the most frequent concern patients wish to discuss in head and neck review clinics.
\end{abstract}

Aim: To design a simple screening question on fear of recurrence to be incorporated into the University of Washington Quality of Life Questionnaire (UW-QOLv4), for use in clinical practice.

Methods: A cross-sectional survey comprising 528 patients.

Results: $11 \%$ selected the two most severe FoR categories. FoR responses correlated strongly (Spearman $r_{s}=-0.82$ ) with the mean score of the 7 items of the Fear of Recurrence Questionnaire. There was also a strong association with anxiety and mood dysfunction as measured from the UW-QOL, and with overall QOL. Patients more affected by FoR tended to be younger and post radiotherapy or chemotherapy.

Conclusion: The FoR screening question should be bolted on to the UW-QOLv4 in order to help identify patients with significant FoR might benefit from further intervention. 


\section{Introduction}

One of the main emotional aspects for cancer survivors is the anxiety related to fear of the cancer coming back. Fear of recurrence (FoR) is described as 'the fear associated with the possibility the cancer will return or progress in the same or another part of the body'. ${ }^{1}$ Fear of recurrence is a significant psychological problem and rates of up to $65 \%$ have been reported.

${ }^{2}$ It is the most frequent issue patients wish to raise in review consultations. ${ }^{3,4}$ This is not unexpected as patients face considerable uncertainty and daily challenges of living with and beyond head and neck cancer (HNC). ${ }^{5}$ Although FoR is a complex issue influenced by a multitude of factors, including demographic, clinical and psychological factors, ${ }^{2}$ there is a body of evidence developing in the literature specific to HNC. ${ }^{5-11}$

It is understandable that patients feel anxious about FoR and this can be considered entirely normal. However, sometimes the anxiety can develop into a clinical problem with symptoms such as ruminative worry, poor concentration, poor morals, depression and poor quality of life. A self-regulation model consisting of psychological controls on thoughts and emotions has been developed to help explain this anxiety response in patients. It is a parallel process model divided into 3 sections; illness representations or concerns, emotional reactions, coping behaviours and an appraisal of he success of this coping. ${ }^{12}$ The degree of success of the patient's coping is appraised and feedback to change the illness representations. The beliefs of the patient with high fears of recurrence are such that they frequently interpret everyday changes in bodily symptoms as a sign of serious disease. They then develop concern for their health and fear serious illness and death; this can be very intrusive in the patient's life. These responses in the form of thoughts and unpleasant emotions then lead consequentially to behaviours such as reassurance-seeking, increased medical consultations and healthcare costs. ${ }^{13,14}$ Anxiety can therefore have an effect on provisions of care in cancer as those who have a high anxiety require greater assistance and consume more health care resources. There has also been evidence to suggest that FoR in patients does not diminish over time so is an ongoing burden for some patients. ${ }^{1,6}$

It is difficult to predict which patients will experience FoR as it does not seem to relate to routine patient characteristics, such as stage and site of disease. ${ }^{6}$ The Patient Concerns Inventory (PCI) gives the opportunity for FoR to be discussed in consultations as prompted by the patient. ${ }^{3,4}$ This facilitates the discussion of the emotional aspects of cancer. ${ }^{15}$ 
However with the PCI, there is no is no measure of severity to allow a focus on patients with more significant problems. For these patients, signposting for additional emotional support could be appropriate as could consideration of specific FoR intervention such as AFTER. ${ }^{16}$ To screen for FoR there are several questionnaires available. ${ }^{17,18}$ However, for simplicity in clinical care it would be very useful to have a single question that could be added to an existing health related quality of life questionnaire such as the University of Washington questionnaire (UW-QOLv4). ${ }^{19}$ The UW-QOL is a commonly used head and neck cancer specific HRQOL questionnaire. Mood and anxiety were added to the original questionnaire ${ }^{19}$ and there is merit in adding an item about FoR. Hence the aim of this study is to provide an individual question to assess FoR in the style of the UW-QOL. This can be added to the UWQOL to help identify those patients with levels of FoR who might benefit from intervention.

\section{Methods}

The university hospital Aintree database was used to access the records of patients treated for primary head and neck squamous cell carcinomas between 2008 and 2012. This gave a cohort of 1545 patients. These patients were analysed to see if they were currently alive or dead using both the hospital Sigma system and ONS data. Of the remaining patients those aged over 85 were excluded from the postal survey as were any patients treated with palliative intent or active recurrence, with cognitive impairment or living overseas and those from previous surveys having volunteered a wish not to receive any more questionnaires. Approval for the survey was given by Aintree University Hospital Clinical Audit Department.

The new UW-QOL style FoR question (Figure 1) was designed in several steps. The authors formulated the initial wording. This was then discussed with patients at both the Units Head and Neck Cancer Support Group and also a Head and Neck Cancer Research Forum. Changes were made and emailed round to patients who were unable to attend the meetings and also the two Head and Neck Clinical Nurse Specialists and our Emotional Support Therapist. The final version was lastly emailed around to the group again.

The UW-QOL is scored on two subscales; physical and socio-emotional function. ${ }^{20}$ The physical function is scored as an average of questions based on swallowing, chewing, speech, saliva, taste and appearance, whilst social-emotional function is the average of activity, recreation, pain, mood, anxiety and shoulder. Criteria derived from earlier work ${ }^{21}$ can 
indicate the domains in which patients have a significant problem or dysfunction, these criteria being based on a mix of domain scores and domain importance over the past week. There is also a single item overall QOL question for which patients are asked to consider not only physical and mental health, but also other factors, such as family, friends, spirituality or personal leisure activities important to their enjoyment of life.

The survey package included the UW-QOL version 4, the new FoR screening question, and also a 7-item 'Fear of Recurrence questionnaire' ${ }^{17}$ suitable for evaluating FoR in the outpatient setting. The 7 questions consisted of statements with a 5-point response scale (not at all, a little, sometimes, a lot, all the time). This was included to enable comparison of the FoR screening question with the more detailed FoR-specific questionnaire, i.e. with a more established measure of the levels of FoR that patients were actually experiencing.

Survey packs containing a free return envelope, the survey, a cover letter and support group information were mailed on 28 February 2014. A reminder pack was sent to non-responders on 12 May 2014. Incoming survey data were entered into SPSS V19 software which was used for the analyses. Spearman correlation was used to assess the strength of association between levels reported for FoR and items from the Fear of Recurrence Questionnaire. The Chi-squared test or Kruskal-Wallis test was used as appropriate to compare characteristics of patients within each FoR category, these being clinical and personal characteristics and also dysfunction, subscale scores and overall QOL pertaining from the UW-QOL. Due to the number of tests performed statistical significance was set at $\mathrm{p}<0.01$.

\section{Results}

The survey response was $60 \%$ (528/878) of which 513 completed the single item question on FoR. Median (IQR) age at time of first mailing for these 513 patients was 65 (58-72) years and $71 \%$ (366) were male. Location of primary tumour was oral $(35 \%, 181)$, oropharyngeal $(36 \%, 185)$, laryngeal $(20 \%, 105)$ or other $(8 \%, 42)$. Overall clinical stage was late (stages 3-

4) for $45 \%$ (216/481), unknown for 32. Primary treatment comprised surgery alone (40\%, 201/499), surgery with adjuvant radiotherapy $(42 \%, 211 / 499)$ or primary CT/RT (17\%, 87/499), unknown for 14. Median (IQR) time from operation (or diagnosis if no operation) to initial survey mailing was 36 (26-49) months. Analyses were performed to compare response to the single FoR question $(58 \%, 513 / 878$ overall) by these clinical and personal characteristics. There were minor variations, though response was notably lower (defined as 
$50 \%$ or less) for those aged under 55 years $(48 \%, 74 / 154)$ and for those more than four years on from treatment $(50 \%, 137 / 275)$.

Responses to the new FoR question and to the 7 items on the more established FoR questionnaire are summarised in Table 1. Only 5\% (28) selected the most concerning category in the new question (i.e. I am fearful all the time) and only another 5\% (26) the next severe category (I get a lot of fears of recurrence and these can really pre-occupy my thought). Almost one third $(29 \%, 147)$ responded to the middle option (I am sometimes having fearful thoughts but I can usually manage these). Most patients though $(61 \%, 312)$ responded to the lesser FoR categories with most (49\%, 249 overall) having a little fear that didn't really bother them and only a minority (12\%, 63 overall) saying they had no fear of recurrence. Spearman correlation was strongest between the new FoR question and statements 1 (I am afraid that my cancer may recur, $\mathrm{r}_{\mathrm{s}}=-0.83, \mathrm{p}<0.001$ ), and 2 (I am worried or anxious about the possibility of cancer recurrence, $\left.r_{s}=-0.80, p<0.001\right)$ from the 7 item FoR questionnaire and weakest with statement 6 (I examine myself to see if I have physical signs of cancer, $r_{s}=-0.46, p<0.001$ ) with correlation coefficients ranging in strength between $r_{s}=-$ 0.68 and $r_{s}=-0.75$ for the other 4 statements. The mean score was computed from the responses to each of the 7 items on the FoR questionnaire and this was also strongly correlated $\left(r_{s}=-0.82, p<0.001\right.$, Figure 2$)$ with the new FoR question.

Responses to the new FoR question showed strong association with many aspects of dysfunction as tapped into by studying UW-QOL domain scores and importance (Table 2). Particularly strong were the associations with anxiety and mood dysfunction. Not unsurprisingly there was therefore stronger discrimination in regard to the social-emotional subscale score than the physical subscale score. There was also a pronounced trend over FoR categories in the percentage reporting good, very good or outstanding overall quality of life.

Patients reporting more severe levels of FoR tended to be younger (Table 3). There were also significant associations with ever having had radiotherapy or chemotherapy as part of the head and neck cancer journey. Overall clinical staging of the primary tumour, primary tumour site and primary treatment showed little association with FoR, as did time from initial treatment, nor the age when patients finished formal education. 


\section{Discussion}

Previous clinic outcomes research has shown that FoR is the most common issue which head and neck cancer patients want to raise within clinic. ${ }^{1,3,4}$ High levels of FoR can have a detrimental effect on HRQOL. ${ }^{9}$ FoR cannot be easily predicted by routine patient characteristics such as gender, site and stage. ${ }^{1,4}$ This was also reflected in this study though patients reporting more severe levels of FoR tended to be younger, post-radiotherapy or chemotherapy. Without clear clinical factors to predict which patients might have FoR there is a need to have a screening tool that can act as a prompt to allow the issue to be discussed. The PCI provides such opportunity. ${ }^{3}$ However once identified it would be helpful to gauge the degree of FoR concern and to include a single screening question bolted on to a well established HRQOL would aid simplicity. The FoR screening question used in this study was developed in collaboration with patients and the multiprofessional team but the census group was based just at one unit. There might be a need in future studies to assess cross-cultural variation in the wording used. The FoR question was assessed in a cross sectional survey of survivors. The cohort is open to survivorship bias with advance cancer being relatively under represented and also there is no longitudinal evaluation. The response rate of $60 \%$ was acceptable for the purpose of correlation with another fear of recurrence measure.

Using the new FoR question, a minority of patients (12\%) reported 'no fear of recurrence'. Nearly half reported 'having a little fear that didn't really bother them'. The group where FoR was substantial were the 5\% reporting 'I am fearful all the time' and another 5\% reporting 'a lot of fears of recurrence and these can really pre-occupy my thought'. There was good correlation between items in the single questionnaire and the 7 question FoR scale (figure 2). Hence it would seem reasonable to suggest the choice of wording in the single UW-QOL style FoR has reasonable validity to help grade severity and form a question that might help screen patients with clinically meaningful FoR. These patients could have additional support and intervention. Where to set the cut off will need further research using a larger sample and longitudinal data but from this study it could be postulated that those patients scoring the worse two items 'I am fearful all the time or a lot of fears of recurrence and these can really pre-occupy my thought', should be considered for added assessment and support.

There is an association between anxiety dysfunction as measured by the UW-QOL and FoR. ${ }^{1}$ A cut-off for anxiety dysfunction has been defined for the UW-QOL. ${ }^{20}$ However in the 
cohort sampled in this study, 16 participants (out of 53) who selected the two highest options of FoR in the screening question did not register as having anxiety dysfunction on the UWQOL. This suggests there is a place for a FoR question as one third of patients within the two most severe categories would have been missed by the anxiety question alone. The middle option of the FoR screening question was selected by 144 patients, and 108 of these recorded fearful thoughts without anxiety being flagged up as a significant problem, showing that most of these patients with more moderate levels of FoR would be missed by the anxiety question alone. This supports the inclusion of a separate FoR question and its inclusion as part of patient-reported outcomes should enhance the clinic consultation. ${ }^{22}$

The new FoR question also correlated strongly with the social subscale of the UWQOL ${ }^{20}$ suggesting that FoR is a relevant social problem within head and neck cancer. However it also correlated to a lesser extent with the physical subscale of the UWQOL suggesting that FoR can be caused by both physical and social sources. This finding confirms that FoR can be linked to symptom experience. That is, patients with complaints about symptoms may think that they indicate a possible new disease process. This supports the Leventhal SelfRegulation Model. Alternatively it could mean that greater fears of recurrence magnify the reporting of other symptom complaints (i.e. reverse 'causation'). The correlation with overall quality of life score suggests this, in that patients overall well-being after cancer has an effect on FoR.

This initial cross sectional survey has shown that this single FoR question could have merit in the clinical care of head and neck cancer patients. Patients with FoR dysfunction can receive extra support and if required formal intervention focused on addressing FoR (AFTER). ${ }^{16}$ Further studies comparing the PCI and the screening question may also provide beneficial results to determine if those patients with FoR actually wish to discuss their problems. There is evidence that supports early intervention ${ }^{22}$ as being most effective for FoR, so longitudinal evaluation of both screening for FoR and intervention is essential to help ascertain the optimal timing to support patients following completion of their cancer treatment.

\section{Conclusion}

The new FoR screening question should be bolted on to the UW-QOLv4. It would not add any substantial questionnaire burden for patients. The inclusion of this question is important as it not only will facilitate discussion in clinics concerning the issue of FoR, it will also 
afford the opportunity for further outcomes research into the optimal intervention aimed at reducing FoR and improving the socio-emotional impact of cancer endured in patients during survivorship.

Conflict of interest: The authors have no conflict of interest to disclose.

\section{References}

1.Rogers SN, Scott B, Lowe D, Ozakinci G, Humphris GM. Fear of recurrence following head and neck cancer in the outpatient clinic. Eur Arch Otorhinolaryngol 2010; 267:1943-9.

2.Crist JV, Grunfeld EA. Factors reported to influence fear of recurrence in cancer patients: a systematic review. Psychooncology 2013; 22:978-86.

3.Rogers SN, El-Sheikha J, Lowe D.The development of a Patients Concerns Inventory (PCI) to help reveal patients concerns in the head and neck clinic. Oral Oncol 2009; 45:555-61.

4.Kanatas A, Ghazali N, Lowe D, Udberg M, Heseltine J, O'Mahony E, Rogers SN. Issues patients would like to discuss at their review consultation: variation by early and late stage oral, oropharyngeal and laryngeal subsites. Eur Arch Otorhinolaryngol 2013; 270:106774.

5.Lang H, France E, Williams B, Humphris G, Wells M. The psychological experience of living with head and neck cancer: a systematic review and meta-synthesis. Psychooncology. 2013; 22: 2648-63.

6.Humphris GM, Rogers, SN, McNally D, Lee-Jones C, Brown, JS, Vaughan ED. Fear of recurrence and possible cases of anxiety and depression in orofacial cancer patients. Int $\mathbf{J}$ Oral Maxillofac Surg 2003; 32: 486-491.

7.Llewellyn CD, Weinman J, McGurk M, Humphris G. Can we predict which head and neck cancer survivors develop fears of recurrence? Journal of psychosomatic research 2008; 65:525-32. 
8.Hodges LJ, Humphris GM. Fear of recurrence and psychological distress in head and neck cancer patients and their carers. Psychooncology 2009; 18:841-8.

9.Handschel J, Naujoks C, Kübler NR, Krüskemper G. Fear of recurrence significantly influences quality of life in oral cancer patients. Oral Oncol 2012; 48:1276-80.

10.Ghazali N, Cadwallader E, Lowe D, Humphris G, Ozakinci G, Rogers SN. Fear of recurrence among head and neck cancer survivors: longitudinal trends. Psychooncology 2013; 22:807-13.

11.Shiraz F, Rahtz E, Bhui K, Hutchison I, Korszun A. Quality of life, psychological wellbeing and treatment needs of trauma and head and neck cancer patients. Br J Oral Maxillofac Surg 2014; 52:513-7.

12. Lee-Jones C, Humphris G, Dixon R, Hatcher MB. Fear of cancer recurrence - a literature review and proposed cognitive formulation. Psychooncology 1997; 6, 95-105.

13.Lebel S, Tomei C, Feldstain A, Beattie S, McCallum M. Does fear of cancer recurrence predict cancer survivors' health care use? Support Care Cancer 2013; 21:901-6.

14.Thewes B, Bell ML, Butow P. Fear of cancer recurrence in young early-stage breast cancer survivors: the role of metacognitive style and disease-related factors. Psychooncology $2013 ; 22: 2059-63$

15.Zhou Y, Humphris G, Ghazali N, Friderichs S, Grosset D, Rogers SN. How head and neck consultants manage patients' emotional distress during cancer follow-up consultations: a multilevel study. Eur Arch Otorhinolaryngol. 2014 Jul 31. [Epub ahead of print]

16.Humphris G, Ozakinci G. The AFTER intervention: a structured psychological approach to reduce fears of recurrence in patients with head and neck cancer. British journal of health psychology 2008; 13: 223-30.

17. Simard S, Thewes B, Humphris G, Dixon M, Hayden C, Mireskandari S, Ozakinci G. 
Fear of cancer recurrence in adult cancer survivors: a systematic review of quantitative studies. J Cancer Surviv 2013; 7:300-22.

18. Thewes B, Zachariae R, Christensen S, Nielsen T, Butow P. The Concerns About Recurrence Questionnaire: validation of a brief measure of fear of cancer recurrence amongst Danish and Australian breast cancer survivors. J Cancer Surviv 2014 Aug 19. [Epub ahead of print]

19. Rogers SN, Gwanne S, Lowe D, Humphris G, Yueh B, Weymuller EA, Jr. The addition of mood and anxiety domains to the University of Washington quality of life scale. Head \& Neck 2002; 24:521-9.

20.Rogers SN, Lowe D, Yueh B, Weymuller EA Jr. The physical function and socialemotional function subscales of the University of Washington Quality of Life Questionnaire. Arch Otolaryngol Head Neck Surg 2010; 136:352-7.

21.Rogers SN, Lowe D. Screening for dysfunction to promote multidisciplinary intervention by using the University of Washington quality of life questionnaire. Arch Otolaryngol Head Neck Surg 2009; 135: 369-375.

22. Ghazali N, Lowe D, Rogers SN. Enhanced patient reported outcome measurement suitable for head and neck cancer follow-up clinics. Head Neck Oncol 2012; 4:32.

23. Savard J, Ivers $H$. The evolution of fear of cancer recurrence during the cancer care trajectory and its relationship with cancer characteristics. J Psychosom Res 2013; 74: 354-60. 
Figure 1. Fear of Cancer Recurrence (FoR) severity scale

Fear of the cancer coming back (Tick one box $\square$ ):

$\square$ I have no fear of recurrence

$\square$ I have a little fear, with occasional thoughts but they don't really bother me

$\square$ I am sometimes having fearful thoughts but I can usually manage these

$\square$ I get a lot of fears of recurrence and these can really preoccupy my thoughts

$\square$ I am fearful all the time that my cancer might return and I struggle with this 
Table 1. Questions about Fear of cancer Recurrence (FoR)

\begin{tabular}{|c|c|c|c|c|c|}
\hline & $\begin{array}{l}\text { (100) I have no } \\
\text { fear of } \\
\text { recurrence }\end{array}$ & $\begin{array}{l}\text { (75) I have a } \\
\text { little fear with } \\
\text { occasional } \\
\text { thoughts but } \\
\text { they don't really } \\
\text { bother me }\end{array}$ & $\begin{array}{l}\text { (50) I am } \\
\text { sometimes } \\
\text { having fearful } \\
\text { thoughts but I } \\
\text { can usually } \\
\text { manage these }\end{array}$ & $\begin{array}{l}\text { (25) I get a lot of } \\
\text { fears of } \\
\text { recurrence and } \\
\text { these can really } \\
\text { preoccupy my } \\
\text { thought }\end{array}$ & $\begin{array}{l}\text { (0) I am fearful } \\
\text { all the time that } \\
\text { my cancer might } \\
\text { return and I } \\
\text { struggle with } \\
\text { this }\end{array}$ \\
\hline New Single FoR screening question & $12 \%(63)$ & $49 \%(249)$ & $29 \%(147)$ & $5 \%(26)$ & $5 \%(28)$ \\
\hline The 7 item FoR questionnaire & (1) Not at all & (2) A little & (3) Sometimes & (4) A lot & (5) All the time \\
\hline 1. I am afraid that my cancer may recur & $14 \%(72)$ & $40 \%(205)$ & $33 \%(169)$ & $8 \%(41)$ & $5 \%(26)$ \\
\hline $\begin{array}{l}\text { 2. I am worried or anxious about the } \\
\text { possibility of cancer recurrence }\end{array}$ & $17 \%(89)$ & $39 \%(198)$ & $32 \%(164)$ & $7 \%(36)$ & $5 \%(24)$ \\
\hline $\begin{array}{l}\text { 3. How often have you worried about } \\
\text { the possibility of getting cancer again }\end{array}$ & $14 \%(72)$ & $37 \%(190)$ & $34 \%(173)$ & $10 \%(49)$ & $5 \%(28)$ \\
\hline $\begin{array}{l}\text { 4. I get waves of strong feelings about } \\
\text { the cancer coming back }\end{array}$ & $40 \%(205)$ & $29 \%(147)$ & $21 \%(105)$ & $6 \%(30)$ & $4 \%(22)$ \\
\hline $\begin{array}{l}\text { 5. I think about the cancer returning } \\
\text { when I didn't mean to }\end{array}$ & $39 \%(200)$ & $31 \%(160)$ & $21 \%(105)$ & $6 \%(33)$ & $2 \%(11)$ \\
\hline $\begin{array}{l}\text { 6. I examine myself to see if I have } \\
\text { physical signs of cancer }\end{array}$ & $26 \%(132)$ & $20 \%(104)$ & $31 \%(158)$ & $16 \%(81)$ & $7 \%(36)$ \\
\hline $\begin{array}{l}\text { 7. To what extent does worry about } \\
\text { getting caner again spill over or intrude } \\
\text { on your thoughts and activities }\end{array}$ & $38 \%(193)$ & $27 \%(140)$ & $24 \%(121)$ & $7 \%(36)$ & $4 \%(20)$ \\
\hline
\end{tabular}


Table 2. Association of new Fear of cancer Recurrence (FoR) question with UW-QOL dysfunction, subscale scores and overall quality of life measure.

\begin{tabular}{|c|c|c|c|c|c|c|}
\hline & $\begin{array}{c}(100) \text { I have } \\
\text { no fear of } \\
\text { recurrence } \\
\mathrm{N}=63\end{array}$ & $\begin{array}{l}\text { (75) I have a } \\
\text { little fear with } \\
\text { occasional } \\
\text { thoughts but } \\
\text { they don't } \\
\text { really bother } \\
\text { me } \\
\mathrm{N}=249\end{array}$ & $\begin{array}{l}\text { (50) I am } \\
\text { sometimes } \\
\text { having fearful } \\
\text { thoughts but I } \\
\text { can usually } \\
\text { manage these } \\
\mathrm{N}=147\end{array}$ & $\begin{array}{l}\text { (25) I get a lot } \\
\text { of fears of } \\
\text { recurrence } \\
\text { and these can } \\
\text { really } \\
\text { preoccupy my } \\
\text { thought } \\
\mathrm{N}=26\end{array}$ & $\begin{array}{c}\text { (0) I am } \\
\text { fearful all the } \\
\text { time that my } \\
\text { cancer might } \\
\text { return and I } \\
\text { struggle with } \\
\text { this } \\
\mathrm{N}=28\end{array}$ & P value* \\
\hline \multicolumn{7}{|c|}{ \%Dysfunction as measured on the UW-QOL } \\
\hline Pain & $6 \%(4 / 63)$ & $7 \%(17 / 248)$ & $18 \%(26 / 146)$ & $28 \%(7 / 25)$ & $39 \%(11 / 28)$ & $<0.001$ \\
\hline Activity & $2 \%(1 / 63)$ & $7 \%(18 / 248)$ & $15 \%(22 / 146)$ & $12 \%(3 / 25)$ & $39 \%(11 / 28)$ & $<0.001$ \\
\hline Recreation & $2 \%(1 / 63)$ & $5 \%(12 / 246)$ & $4 \%(6 / 147)$ & $8 \%(2 / 25)$ & $36 \%(10 / 28)$ & $<0.001$ \\
\hline Shoulder & $3 \%(2 / 60)$ & $10 \%(23 / 238)$ & $19 \%(27 / 140)$ & $17 \%(4 / 24)$ & $33 \%(9 / 27)$ & $<0.001$ \\
\hline Mood & $0 \%(0 / 62)$ & $2 \%(4 / 243)$ & $19 \%(28 / 145)$ & $52 \%(13 / 25)$ & $61 \%(17 / 28)$ & $<0.001$ \\
\hline Anxiety & $0 \%(0 / 63)$ & $1 \%(3 / 246)$ & $25 \%(36 / 144)$ & $60 \%(15 / 25)$ & $79 \%(22 / 28)$ & $<0.001$ \\
\hline Appearance & $0 \%(0 / 63)$ & $4 \%(10 / 248)$ & $11 \%(16 / 147)$ & $24 \%(6 / 25)$ & $32 \%(9 / 28)$ & $<0.001$ \\
\hline Swallowing & $0 \%(0 / 62)$ & $5 \%(13 / 248)$ & $10 \%(14 / 147)$ & $12 \%(3 / 25)$ & $36 \%(10 / 28)$ & $<0.001$ \\
\hline Chewing & $0 \%(0 / 61)$ & $4 \%(9 / 245)$ & $9 \%(13 / 145)$ & $8 \%(2 / 25)$ & $18 \%(5 / 28)$ & 0.003 \\
\hline Speech & $3 \%(2 / 61)$ & $4 \%(9 / 245)$ & $8 \%(12 / 144)$ & $4 \%(1 / 25)$ & $29 \%(8 / 28)$ & $<0.001$ \\
\hline Taste & $3 \%(2 / 61)$ & $8 \%(20 / 244)$ & $10 \%(15 / 145)$ & $12 \%(3 / 25)$ & $29 \%(8 / 28)$ & 0.004 \\
\hline Saliva & $13 \%(8 / 62)$ & $16 \%(38 / 244)$ & $24 \%(34 / 142)$ & $24 \%(6 / 25)$ & $41 \%(11 / 27)$ & 0.007 \\
\hline $\begin{array}{l}\text { \% good, very good or outstanding } \\
\text { overall QoL }\end{array}$ & $92 \%(58 / 63)$ & $87 \%(216 / 247)$ & $62 \%(91 / 146)$ & $46 \%(12 / 26)$ & $25 \%(7 / 28)$ & $<0.001$ \\
\hline $\begin{array}{l}\text { Median (IQR) Physical function } \\
\text { subscale score }(0-100)^{* *}\end{array}$ & $90(80-100)$ & $90(73-96)$ & $77(59-88)$ & $75(57-88)$ & $56(36-74)$ & $<0.001^{* *}$ \\
\hline $\begin{array}{l}\text { Median (IQR) Social-emotional** } \\
\text { function subscale score }(0-100)\end{array}$ & $95(83-100)$ & 87 (75-95) & $74(58-86)$ & $58(50-79)$ & $43(33-60)$ & $<0.001^{* *}$ \\
\hline
\end{tabular}

* Chi-squared test, apart from ** Kruskal-Wallis test 
Table 3. Association of new Fear of cancer Recurrence (FoR) question with clinical and personal characteristics.

\begin{tabular}{|c|c|c|c|c|c|}
\hline & $\begin{array}{c}\text { (100) I have no } \\
\text { fear of recurrence } \\
N=63\end{array}$ & $\begin{array}{l}\text { (75) I have a little } \\
\text { fear with } \\
\text { occasional } \\
\text { thoughts but they } \\
\text { don't really } \\
\text { bother me } \\
\mathrm{N}=249\end{array}$ & $\begin{array}{l}\text { (50) I am } \\
\text { sometimes having } \\
\text { fearful thoughts } \\
\text { but I can usually } \\
\text { manage these } \\
\mathrm{N}=147\end{array}$ & $\begin{array}{l}\text { (25) I get a lot of } \\
\text { fears of } \\
\text { recurrence and } \\
\text { these can really } \\
\text { preoccupy my } \\
\text { thought } \\
\mathrm{N}=26\end{array}$ & $\begin{array}{l}\text { I am fearful all } \\
\text { the time that my } \\
\text { cancer might } \\
\text { return and I } \\
\text { struggle with this }\end{array}$ \\
\hline$\%$ female & $19 \%(12 / 63)$ & $25 \%(63 / 249)$ & $35 \%(52 / 147)$ & $31 \%(8 / 26)$ & $43 \%(12 / 28)$ \\
\hline$\%$ aged $<55$ years at survey & $6 \%(4 / 63)$ & $12 \%(29 / 249)$ & $16 \%(24 / 147)$ & $36 \%(9 / 25)$ & $29 \%(8 / 28)$ \\
\hline$\%$ aged $55-64$ & $25 \%(16 / 63)$ & $32 \%(80 / 249)$ & $42 \%(61 / 147)$ & $40 \%(10 / 25)$ & $39 \%(11 / 28)$ \\
\hline$\%$ aged $\geq 65$ & $68 \%(43 / 63)$ & $56 \%(140 / 249)$ & $42 \%(62 / 147)$ & $23 \%(6 / 26)$ & $32 \%(9 / 28)$ \\
\hline Median (IQR) age at survey & $69(62-74)$ & $66(61-73)$ & $63(57-69)$ & $58(51-66)$ & $60(54-67)$ \\
\hline Late clinical stage $3-4$ & $44 \%(24 / 55)$ & $39 \%(93 / 236)$ & $51 \%(71 / 138)$ & $52 \%(13 / 25)$ & $56 \%(15 / 27)$ \\
\hline$\%$ Oral tumour site & $30 \%(19 / 63)$ & $41 \%(102 / 249)$ & $29 \%(43 / 147)$ & $35 \%(9 / 26)$ & $29 \%(8 / 28)$ \\
\hline \% Oropharyngeal site & $33 \%(21 / 63)$ & $31 \%(76 / 249)$ & $44 \%(65 / 147)$ & $38 \%(10 / 26)$ & $46 \%(13 / 28)$ \\
\hline \% laryngeal site & $30 \%(19 / 63)$ & $20 \%(51 / 249)$ & $17 \%(25 / 147)$ & $19 \%(5 / 26)$ & $18 \%(5 / 28)$ \\
\hline \multicolumn{6}{|l|}{ Primary treatment } \\
\hline$\%$ surgery only & $53 \%(32 / 60)$ & $55 \%(131 / 240)$ & $43 \%(61 / 143)$ & $42 \%(11 / 26)$ & $39 \%(11 / 28)$ \\
\hline$\%$ surgery $\&$ adjuvant & $28 \%(17 / 60)$ & $32 \%(77 / 240)$ & $36 \%(51 / 143)$ & $31 \%(8 / 26)$ & $39 \%(11 / 28)$ \\
\hline$\%$ RT-CT only & $18 \%(11 / 60)$ & $13 \%(32 / 240)$ & $22 \%(31 / 143)$ & $27 \%(7 / 26)$ & $21 \%(6 / 28)$ \\
\hline Median (IQR) months from treatment & $36(26-51)$ & $38(27-52)$ & $33(25-46)$ & $30(22-42)$ & $38(22-45)$ \\
\hline \% ever having RT as part of H\&N cancer & $56 \%(35 / 62)$ & $57 \%(141 / 248)$ & $71 \%(104 / 146)$ & $65 \%(17 / 26)$ & $89 \%(25 / 28)$ \\
\hline$\%$ ever having $\mathrm{CT}$ as part of $\mathrm{H} \& \mathrm{~N}$ cancer & $15 \%(9 / 60)$ & $12 \%(29 / 246)$ & $26 \%(37 / 143)$ & $27 \%(7 / 26)$ & $39 \%(11 / 28)$ \\
\hline $\begin{array}{l}\text { \% saying head and neck cancer ever } \\
\text { recurred (ever come back) }\end{array}$ & $5 \%(3 / 62)$ & $8 \%(20 / 242)$ & $13 \%(18 / 144)$ & $12 \%(3 / 26)$ & $21 \%(6 / 28)$ \\
\hline \multicolumn{6}{|l|}{ Age when left school/college/univeristy } \\
\hline$<16$ yrs & $49 \%(30 / 61)$ & $49 \%(118 / 243)$ & $39 \%(56 / 142)$ & $38 \%(10 / 26)$ & $52 \%(14 / 27)$ \\
\hline $16-17$ yrs & $31 \%(19 / 61)$ & $30 \%(73 / 243)$ & $33 \%(47 / 142)$ & $42 \%(11 / 26)$ & $37 \%(10 / 27)$ \\
\hline$\geq 18$ yrs & $20 \%(12 / 61)$ & $21 \%(52 / 243)$ & $27 \%(39 / 142)$ & $19 \%(5 / 26)$ & $11 \%(3 / 27)$ \\
\hline
\end{tabular}

* Chi-squared test, apart from ** Kruskal-Wallis test 
Figure 2. Correlation of the new single screening question about Fear of cancer Recurrence (FoR) with the mean score of the 7 FoR questions in 'The FoR Questionnaire'

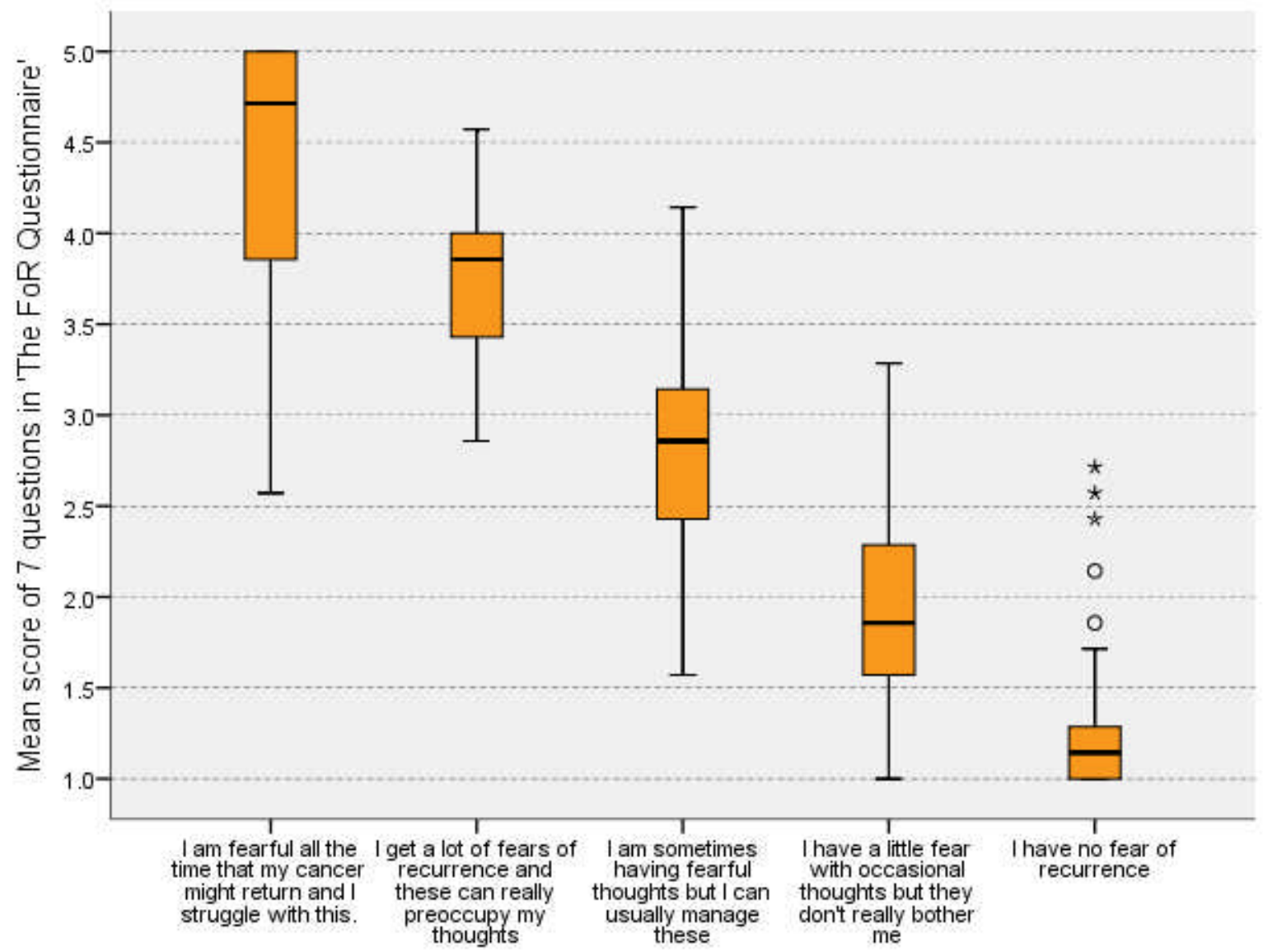

New Single Screening question: Fear of the cancer coming back

Spearman correlation, $r_{s}=-0.82, p<0.001$ 